Research Article

\title{
Evaluation of the knowledge, attitude and the practice of pharmacovigilance among the interns and doctors in a tertiary level care teaching hospital in Northern India
}

\author{
Manreet Singh Sekhon*, Anita K. Gupta, Neetu Sharma
}

\begin{abstract}
Department of Pharmacology, Government Medical College, Patiala, Punjab, India
\end{abstract}

Received: 06 April 2016 Accepted: 07 May 2016

*Correspondence to:

Dr. Manreet Singh Sekhon, Email: dr_mssekhon @yahoo.com

Copyright: (C) the author(s), publisher and licensee Medip Academy. This is an openaccess article distributed under the terms of the Creative Commons Attribution NonCommercial License, which permits unrestricted noncommercial use, distribution, and reproduction in any medium, provided the original work is properly cited.

\begin{abstract}
Background: Adverse drug reaction (ADR) is defined by world health organization (WHO) as "a response to a drug, which is noxious and unintended, and which occurs at doses normally used in man for the prophylaxis, diagnosis or therapy of disease or for the modification of physiological function. The objective of this study was investigating the knowledge, attitudes and practices of doctors and interns to ADR reporting and reasons for underreporting of ADRs.

Methods: It was a questionnaire-based, cross-sectional study. Questionnaires was designed, validated by doing a pilot study, administered to doctors and interns working in a teaching hospital with an ADR monitoring center. This questionnaire was administered to randomly select 500 faculty members, interns and the resident doctors for inclusion in the study, out of which only 209 responded. The study was approved by institutional ethics committee, government medical college Patiala. Only those who gave their consent to participate were included in the study. The data was analysed by using the statistical package for social sciences (SPSS) statistical software, version 20.

Results: Only $20 \%$ faculty members and 51\% interns were aware of AMC in our institute. Legal inquiry/action involved for reporting an ADR was the main worry while reporting an ADR for faculty member $(68 \%)$. Lack of time to report ADR was the main reason given by Interns (22\%) and not knowing to whom and where to report was the main reason given by Interns PGs (40\%). Awareness of postgraduate residents $(90 \%)$ was overall better than faculty and interns.

Conclusions: There is a great need to create awareness and to promote the reporting of ADR amongst interns and doctors, which will lay a solid foundation for these healthcare professionals to be involved in quality pharmacovigilance.
\end{abstract}

Keywords: Pharmacovigilance, ADR reporting, Doctors

\section{INTRODUCTION}

Adverse drug reaction (ADR) is defined by world health organization (WHO) as "a response to a drug, which is noxious and unintended, and which occurs at doses normally used in man for the prophylaxis, diagnosis or therapy of disease or for the modification of physiological function."1 ADRs are one of the major health care problems occurring throughout the world. They affect the people with varying magnitudes, causing both morbidity and mortality.,
Pharmacovigilance is the science and activities related to the detection, assessment, understanding, and prevention of adverse effects or any other possible drug-related problems. $^{4}$ To transform the concept of pharmacovigilance into practice for enhancing the safety of patients, ADR monitoring centers (AMCs) are being set up across the country under pharmacovigilance programme of India (PvPI). ${ }^{5}$

Spontaneous reporting of ADRs has played a major role in the detection of unsuspected, serious, and unusual ADRs which were previously undetected during the 
clinical trial phases. This has led to the withdrawal of many drugs in the recent past, i.e., rofecoxib, cisapride, terfenadine. ${ }^{6}$ The contribution of health professionals is enormous in this regard. However, underreporting still remains a major obstacle in the complete success of pharmacovigilance program. ${ }^{7}$ It is found that only $6-10 \%$ of all ADRs are reported. ${ }^{8,9}$ This high rate of underreporting is a matter of great concern which can delay detection of serious ADRs and consequently have a major negative impact on the public health.

Various factors have been attributed for underreporting of ADRs among health professionals. These factors are based on knowledge and perception of health professionals to reporting. Inman has described them as "seven deadly sins." These include: Financial incentives: No rewards for reporting are given; legal aspects: Fear of litigation or enquiry into prescribing costs; complacency: The belief that very serious ADRs are well documented by the time a drug is marketed; diffidence: The belief that reporting an ADR would only be done if there was certainty that it was related to the use of a particular drug; indifference: The belief that the single case an individual doctor might observe could not contribute to medical knowledge; ignorance: The belief that it is only necessary to report serious or unexpected ADRs, and excuses made by professionals; and lethargy: The procrastination and disinterestedness in reporting or lack of time to find a report card, and other excuses. ${ }^{10}$

The factors responsible for underreporting have not been extensively studied in India. Also various socio-economic factors, religious beliefs, superstitions and cultural variations have a role to play in the underreporting of ADRs especially in the Indian set-up.

In order to improve the reporting rate, it is important to improve the knowledge, attitude and practices (KAP) of the healthcare professionals regarding ADR reporting and Pharmacovigilance. The best time to do it is probably during the under graduate and post graduate education of the doctors. The primary objective of this study was to evaluate the baseline KAP of the interns and doctors (including faculty members and post graduates). The second primary objective was to find the reasons for underreporting at a teaching hospital in Punjab, regarding ADR monitoring and Pharmacovigilance. This would help us in planning interventions amongst this group of doctors.

\section{METHODS}

A cross sectional, questionnaire based survey was carried out at a government teaching and tertiary level care hospital in the state of Punjab, India Govt. Medical College and Rajindra Hospital, Patiala, Punjab, India.

\section{Study population}

Two hundred and nine questionnaires were administered to the interns and doctors from clinical departments and para clinical departments, including the resident doctors who were pursuing their post-graduation in any of the medical, surgical, para clinical fields.

\section{Study instrument}

The study instrument was a pre designed questionnaire which was structured to obtain the information about their knowledge of ADR reporting, attitudes to reporting, and the factors that they perceived may influence reporting. Provision will also make for suggestions on possible ways to improve ADR reporting. Questionnaire was validated through a pilot study.

\section{Study conduct}

The questionnaire was administered to all the interns and doctors in the resident doctor's hostels, all the clinical wards, outpatient departments, operation theatres and departments (convenience sampling). The doctors were requested to complete the questionnaire and hand it back immediately, to maximize the response rate. Those who will busy at that moment were requested to return back the duly filled questionnaires within 1 week.

\section{RESULTS}

About 500 faculty member, interns and the resident doctors who were pursuing their post-graduation in any of the medical, surgical, para clinical fields were randomly selected for inclusion in the study. A total of 209 of 500 selected faculty member, interns and the Postgraduate resident doctors provided response to the questionnaire. The response rate with respect to 500 finally selected faculty member, interns and the resident doctors was $40 \%$. The responses from total of 209 faculty member (70), interns (69) and the resident doctors (70) were used for further statistical analysis. Responses faculty member, interns and the resident doctors to questions related to knowledge or awareness about ADR reporting are summarized in (Table 1).

As far as awareness of pharmacovigilance is concerned study reveals that only $36 \%$ of the faculty members were aware of the meaning of pharmacovigilance. (Table 1) futher reveals that knowledge of ADR monitoring centers (AMC) in our institution was also very limited. Only 20\% faculty members and $51 \%$ interns were aware of AMC in our institute. Awareness of postgraduate residents (90\%) was overall better than faculty and interns. Knowledge About the healthcare professionals responsible for reporting ADRs in a hospital was also very limited and $34 \%$ faculty members , 64\% interns and $88 \%$ PGs were aware of this. 
Table 1: questions related to knowledge and percentage of correct responses among faculty members, interns and PGs.

\begin{tabular}{|lllll|}
\hline Q. No. & knowledge or awareness questions & \multicolumn{3}{c|}{ Correct answer Percentage } \\
\hline 1. & What is Pharmacovigilance? & Faculty & Interns & PGs \\
\hline 2 & Where is the international center for adverse drug reaction located & 36 & 69 & 96 \\
\hline 3. & Which regulatory body is responsible for ADR monitoring in India? & 36 & 65 & 64 \\
\hline 4. & $\begin{array}{l}\text { Is there any adverse drug reactions (ADRs) reporting and monitoring system } \\
\text { at your hospital? }\end{array}$ & 20 & 51 & 59 \\
\hline 5. & Rare ADRs can be identified in the following phase of a clinical trial & 25 & 68 & 78 \\
\hline & $\begin{array}{l}\text { Who are the healthcare professionals responsible for reporting ADRs in a } \\
\text { hospital }\end{array}$ & 34 & 64 & 88 \\
\hline 7. & Do you know about the Thalidomide Disaster? & 38 & 68 & 95 \\
\hline
\end{tabular}

Table 2: Questions related to attitude and percentage of correct responses among faculty members, interns and PGs.

\begin{tabular}{|c|c|c|c|c|}
\hline \multirow{2}{*}{ Q. No. } & \multirow{2}{*}{ Attitudes regarding adverse event reporting } & \multicolumn{3}{|c|}{ Percentage response as yes/ correct answer } \\
\hline & & Faculty & Interns & PGs \\
\hline 8 & $\begin{array}{l}\text { Which among the following factors discourage you from } \\
\text { reporting adverse drug reactions? (any one only) }\end{array}$ & & & \\
\hline $8(\mathbf{a})$ & Legal inquiry/action involved for reporting an ADR & 68 & 10 & 17 \\
\hline $8(\mathbf{b})$ & Lack of time to report ADR & 4 & 22 & 20 \\
\hline $8(c)$ & Difficult to decide whether ADR has occurred or not & 5 & 10 & 16 \\
\hline $8(d)$ & Not knowing where and whom to report & 18 & 24 & 40 \\
\hline 9 & $\begin{array}{l}\text { Do you think reporting of adverse drug reaction is } \\
\text { necessary? }\end{array}$ & 38 & 68 & 100 \\
\hline 10 & Do you think reporting is a professional obligation for you? & 4 & 18 & 22 \\
\hline 11 & ADR reporting should be & & & \\
\hline 11a & Voluntary & 11 & 12 & 19 \\
\hline 11b & Compulsory & 26 & 56 & 82 \\
\hline 11c & Remunerated & 1 & 0 & 0 \\
\hline 11d & No need to report & 0 & 0 & 1 \\
\hline 12 & $\begin{array}{l}\text { Do you think pharmacovigilance should be taught in detail } \\
\text { to healthcare professionals? }\end{array}$ & 38 & 68 & 102 \\
\hline
\end{tabular}

Table 3: Questions related to practice of $P V$ and percentage of correct responses among faculty members, interns and PGs.

\begin{tabular}{|lllll|}
\hline Q. No. & Attitudes regarding reporting mechanism & \multicolumn{3}{l|}{ Percentage response as yes/ correct answer } \\
\hline 13 & Have you ever come across with an ADR? & Faculty & Interns & PGs \\
\hline 14 & $\begin{array}{l}\text { Have you ever been taught / trained on how to report } \\
\text { adverse drug reaction (ADR)? }\end{array}$ & 6 & 26 & 61 \\
\hline 15 & $\begin{array}{l}\text { Have you reported any suspected adverse drug reactions to } \\
\text { any of the ADR reporting and monitoring centres? }\end{array}$ & 3 & 1 & 12 \\
\hline
\end{tabular}

Table 2 shows attitudes of faculty member, interns and the resident doctors regarding adverse event reporting. Table 2 reveals that the reasons for underreporting by faculty member, interns and the resident doctors were different. Legal inquiry/action involved for reporting an ADR was the main worry while reporting an ADR for faculty member (68\%). Lack of time to report ADR was the main reason given by Interns $(22 \%)$ and not knowing to whom and where to report was the main reason given by Interns PGs $(40 \%)$.

$100 \%$ Postgraduates think that reporting of adverse drug reaction is necessary compared to $38 \%$ and $68 \%$ of the faculty members and interns respectively. $22 \%$ Postgraduates think that reporting is a professional obligation for them compared to $4 \%$ and $18 \%$ of the 
faculty members and interns respectively. ADR reporting should be compulsory according to $82 \%$ of PGs compared to $26 \%$ and $56 \%$ of the faculty members and interns respectively. $102 \%$ of PGs think Pharmacovigilance should be taught in detail to healthcare professionals while only $38 \%$ and $68 \%$ of the faculty members and interns think this as important.

Table 3 further reveals that about $29 \%$ faculty members ever came across with an ADR. Only $3 \%$ of them reported these ADRs to ADR centers and only $6 \%$ have ever been taught/trained on how to report adverse drug reaction. $61 \%$ PGs ever came across with an ADR. Only $18 \%$ of them reported these ADRs to ADR centers and only $12 \%$ have ever been taught / trained on how to report Adverse Drug Reaction. The fact that only $22 \% \%$ of responders have reported ADRs to ADR centers shows that the ADRs are always grossly underreported.

Various suggestions given by the doctors include, creating general public awareness, inclusion of pharmacovigilance in the undergraduate teaching curriculum and regular training about ADR reporting for the health care professionals.

\section{DISCUSSION}

Reporting of ADR is an essential component of pharmacovigilance and is crucial to the safety surveillance of marketed medicinal products. Spontaneous ADR reporting is a vital method for detecting new safety issues related to drugs. ADRs contribute significantly to morbidity and mortality in clinical practice with its associated economic consequences. ${ }^{11,12}$

Many studies have evaluated the knowledge of healthcare professionals about pharmacovigilance. But reporting the same exclusively in resident doctors was reported in very few studies. ${ }^{13}$ Response rate of $77.2 \%$ was reported in one study carried out in resident doctors. ${ }^{13}$ Desai et al also reported a response rate in resident doctors $(77.7 \%)$ compared to that in faculty members. ${ }^{14}$

Studies from developed economies such as UK and USA have reported a higher rate of ADR reporting and higher awareness among healthcare professionals about pharmacovigilance. ${ }^{15,16}$ Even a study from India has reported encouraging findings regarding attitudes and perceptions of medical practitioners about pharmacovigilance. ${ }^{17}$ But many other studies from India as well as other countries. ${ }^{12,14,17,18}$ have reported lower rates of $\mathrm{ADR}$ reporting and awareness among healthcare professionals about pharmacovigilance.

\section{CONCLUSION}

In conclusion, our study strongly suggests that there is a great need to create awareness and to promote the reporting of ADR amongst interns and doctors, which will lay a solid foundation for these healthcare professionals to be diligently involved in quality pharmacovigilance in their future practices. Training sessions to clarify the role of various healthcare professionals in pharmacovigilance, the events to be looked for and reported and to address the various perceived obstacles to spontaneous reporting, will hopefully fill the observed lacunae in knowledge and practices. Attitudinal and cultural changes, whereby ADR reporting is seen as an integral part of the clinical activities of the doctors, are very necessary for a long term improvement of ADR reporting.

Funding: No funding sources

Conflict of interest: None declared

Ethical approval: Not required

\section{REFERENCES}

1. International drug monitoring: The role of National Centres. Report No: 498. Geneva, Switzerland: World Health Organization; World Health Organization; 1972.

2. Pirmohamed M, James S, Meakin S, Green C, Scott $\mathrm{AK}$, Walley $\mathrm{TJ}$, et al. Adverse drug reactions as cause of admission to hospital: Prospective analysis of 18820 patients. Br Med J. 2004;329:15-9.

3. Lazarou J, Pomeranz BH, Corey PN. Incidence of adverse drug reactions in hospitalized patients: A meta-analysis of prospective studies. JAMA. 1998;279:1200-5.

4. The importance of pharmacovigilance. Safety monitoring of medicinal products. Geneva: World Health Organization; World Health Organization Collaborating Centre for International Drug Monitoring; 2002.

5. Pharmacovigilance programme of India 2010. CDSCO, Ministry of Health and Family Welfare, Government of India; 2010.

6. Wysowsky DK, Swartz L. Adverse drug event surveillance and drug withdrawals in the United States, 1969-2002: The importance of reporting suspected reactions. Arch Intern Med. 2005;165:1363-9.

7. Lopez-Gonzalez E, Herdeiro MT, Figueiras A. Determinants of under-reporting of adverse drug reactions: A systematic review. Drug Saf. 2009;32:19-31.

8. Smith CC, Bennett PM, Pearce HM, Harrison PI, Reynolds DJ, Aronson JK, et al. Adverse drug reaction in a hospital general medical unit meriting notification to the Committee on Safety of Medicines. Br J ClinPharmacol. 1996;42:423-42.

9. Feely J, Moriarty S, O'Connor P. Stimulating reporting of adverse drug reaction by using a fee. $\mathrm{Br}$ Med J. 1990;300:22-3.

10. Inman WH. Attitudes to adverse drug-reaction reporting. Br J Clin Pharmacol. 1996;41:433-5.

11. World Health Organization. Safety of medicines. A Guide to Detecting and Reporting Adverse Drug Reactions. Geneva, Switzerland: World Health Organization; 2002. 
12. Moore N, Lecointre D, Noblet C, Mabille M. Frequency and cost of serious adverse drug reactions in a department of general medicine. $\mathrm{Br} \mathrm{J}$ Clin Pharmacol. 1998;45:301-8.

13. Gupta P, Udupa A. Adverse drug reaction reporting and pharmacovigilance: Knowledge, attitudes and perceptions amongst resident doctors. J Pharm Sci Res. 2011;3:1064-9.

14. Desai CK, Iyer G, Panchal J, Shah S, Dikshit RK. An evaluation of knowledge, attitude, and practice of adverse drug reaction reporting among prescribers at a tertiary care hospital. Perspect Clin Res. 2011;2:129-36.
15. Bateman DN, Sanders GL, Rawlins MD. Attitudes to adverse drug reaction reporting in the Northern Region. Br J Clin Pharmacol. 1992;34:421-6.

16. Milstein JB, Faich GA, Hsu JP. Factors affecting physician reporting of adverse drug reactions. Drug Inf J. 1986;20:157-64.

17. Madhan R, Parthasarathi G. Adverse drug reactions reporting: attitudes and perceptions of medical practitioners. Asian J Pharm Clin Res. 2009;2:10-4.

18. Hazell L, Shakir SA. Under-reporting of adverse drug reactions: A systematic review. Drug Saf. 2006;29:385-96.

Cite this article as: Sekhon MS, Gupta AK, Sharma N. Evaluation of the knowledge, attitude and the practice of pharmacovigilance among the interns and doctors in a tertiary level care teaching hospital in Northern India. Int J Basic Clin Pharmacol 2016;5:1068-74. 


\section{QUESTIONNAIRE}

Name:

Age:

Sex:

Year of Residency/Intern/Faculty Member

Department

(Please tick mark the correct response)

\section{Knowledge about adverse event reporting among the resident doctors and interns.}

1) What is Pharmacovigilance?

a) The science of studying clinical trials

b) The process of inspection of Drugs

c) The detection and reporting of adverse effects

d) None of the above

2) Where is the international center for adverse drug reaction located
a) Unites States of America
b) United Kingdom
c) India
d) Sweden

3) Which regulatory body is responsible for ADR monitoring in India?

a) Central Drugs Standard Control Organization (CDSCO)

b) All IndiaInstitute of Medical Sciences (AIIMS)

c) Drug Controller General of India

d) Medical Council of India (MCI)

4) Is there any adverse drug reactions (ADRs) reporting and monitoring system at your hospital?
a) Yes
b) No

5) Rare ADRs can be identified in the following phase of a clinical trial
a) During phase- 1 clinical trials
b) During phase- 2 clinical trials
c) During phase- 3 clinical trials
d) During phase- 4 clinical trials

6) Who are the healthcare professionals responsible for reporting ADRs in a hospital
a) Doctors
b) Pharmacists
c) Nurses
d) All of the above

7) Do you know about the Thalidomide Disaster?
a) Yes
b) No

\section{Attitudes regarding adverse event reporting}

8) Which among the following factors discourage you from reporting Adverse Drug Reactions? (Any one only)
a) Legal Inquiry/Action involved for reporting an ADR
b) Lack of time to report ADR
c) Difficult to decide whether ADR has occurred or not
d) Not Knowing where and whom to report
e) Patient's confidentiality not to be disclosed
f) Non-remuneration for reporting
g) Socio-economic, cultural and religious beliefs involved

9) Do you think reporting of adverse drug reaction is necessary?
a) Yes
b) No

10) Do you think reporting is a professional obligation for you?
a) Yes
b) $\mathrm{No}$
c) Don't know
d) Perhaps

11) ADR reporting should be

a) Voluntary 
b) Compulsory

c) Remunerated

d) No need to report

12) Do you think Pharmacovigilance should be taught in detail to healthcare professionals?
a) Yes
b) No

\section{Practices regarding reporting mechanism}

13) Have you ever come across with an ADR?
a) Yes
b) No

14) Have you ever been trained on how to report Adverse Drug Reaction (ADR)?

a) Yes

Any suggestions: b) No

15) Have you reported any suspected adverse drug reactions to any of the ADR reporting and monitoring centres?
a) Yes
b) No 